\title{
HANNAH ARENDT E A QUESTÃO NEGRA NA DESSEGREGAÇÃO DA ESCOLA DE LITTLE ROCK, 1957
}

\author{
HANNAH ARENDT AND THE BLACK QUESTION IN LITTLE ROCK SCHOOL \\ DESEGRAGATION, 1957
}

Danilo Arnaldo Briskievicz ${ }^{1}$ e Amauri Carlos Ferreira ${ }^{2}$

1 IFMG - Instituto Federal de Minas Gerais, campus Santa Luzia, Brasil. E-mail: doserro@hotmail.com

2 PUC - Pontifícia Universidade Católica de Minas Gerais, Brasil. E-mail: mitolog@pucminas.br

\section{ART I CLE IN F O \\ Article history: \\ Received 2018-07-03 \\ Accepted 2019-06-17 \\ Available online 2019-06-17}

\begin{abstract}
Palavras-chave: Movimentos sociais. Questão negra.
\end{abstract} Política. Educação. Ação.

Keywords: Social movements. Black issue. Policy. Education. Action.

RESUMO. O objetivo deste artigo é discutir o caso de dessegregação racial educacional acontecido na capital do Arkansas, Little Rock, nos Estados Unidos da América, em 4 de setembro de 1957. Para iluminar o contexto social e político das discussões sobre o polêmico caso, retomamos o controverso ensaio de Hannah Arendt publicado em 1959, intitulado Reflexões sobre Little Rock. Contamos, brevemente, a luta dos movimentos sociais norte-americanos ligados à questão negra até o caso Little Rock. Apresentamos variadas relações entre o caso Little Rock e algumas categorias do pensamento arendtiano como igualdade de direitos, mundo comum, responsabilidade, ação, discurso, visibilidade e crise do mundo moderno. Esclarecemos que o mundo comum é uma história comum tecida como resultado da ação e do discurso, em que os agentes se revelam pela palavra, pela voz $e$ pelo gesto. Por fim, evidenciamos que duas mulheres foram escolhidas para narrar Little Rock: Elizabeth Eckford, a estudante de 15 anos que foi hostilizada publicamente e teve seu gesto imortalizado numa fotografia; e outra, Hannah Arendt. A imagem de Eckford foi republicada em diversos jornais, foi vista por Hannah Arendt que reconheceu Little Rock como um caso emblemático para a política e escreveu seu artigo.

\begin{abstract}
The purpose of this article is to discuss the case of educational racial desegregation that took place in Arkansas, Little Rock, United States of America, on September 4, 1957. To illuminate the social and political context of the controversial case, we resume the controversial essay by Hannah Arendt published in 1959, entitled Reflections on Little Rock. We briefly recount the struggle of the American social movements linked to the black issue until the Little Rock case. We present various relationships between the Little Rock affair and some categories of Arendtian thought as equal rights, common world, responsibility, action, discourse, visibility and crisis of the modern world. We clarify that the common world is a common history woven as a result of action and discourse, in which agents are revealed by word, voice and gesture. Finally, we note that two women were chosen to narrate Little Rock: Elizabeth Eckford, the 15-year-old student who was publicly harassed and had her gesture immortalized in a photograph; and another, Hannah Arendt. The Eckford's image was republished in several newspapers, was seen by Hannah Arendt who recognized Little Rock as an emblematic case for politics and wrote her article.
\end{abstract}




\section{Introdução}

Foi no dia 4 de setembro de 1957, na cidade de Little Rock, capital do Arkansas, nos Estados Unidos da América. Elizabeth Eckford, 15 anos, e mais 8 adolescentes negros exigiam o ingresso na Escola Little Rock Central High School (MARGOLICK, 2011). O grupo dos "Little Rock Nine" foi alvo de ataques racistas. Por sua dimensão histórica, a dessegregação de Little Rock é um importante momento para os movimentos sociais no mundo e um dos principais marcos na luta contra o racismo nos Estados Unidos da América.

Uma das mais importantes pensadoras da política no século XX é Hannah Arendt (1906-1975). Após a ascensão do totalitarismo nazista na Alemanha, em 1933, ela se mudou de Berlim para Paris. A sua condição de judia expatriada foi vivenciada em meio aos movimentos sociais de resistência contra o nazismo. Na França chegou a ser prisioneira do campo de concentração em Gurs. Ao conseguir escapar do campo, fugiu para os Estados Unidos da América, chegando em 1941 (YOUNG-BRUEHL, 1997, p. 165). Residindo em Nova York, Arendt escreveu o polêmico texto Reflexões sobre Little Rock, publicado em 1959, pela revista Dissent (GINES, 2014).

Temos um evento. Temos um texto polêmico. Cabe-nos, agora, investigar o evento e o texto, relacionando as perspectivas de Arendt sobre Little Rock.

\section{Origens de Little Rock: segregação racial sulista e os resultados da luta pela igualdade}

A fundação da nação norte-americana iniciou-se com os colonos ingleses estabelecidos nas Treze Colônias, na costa Leste. O desenvolvimento econômico foi diferente no Norte e no Sul. Ao Norte, predominou o modelo da pequena propriedade privada baseada no trabalho livre e assalariado e a industrialização. Ao Sul, o modelo adotado foi o da monocultura com predomínio dos latifúndios e o uso da mão de obra escrava africana.

A Guerra Civil Americana (1861-1865) colocou em disputa os estados do Norte e do Sul. O projeto separatista sulista foi derrotado e após a guerra deu-se início à refundação norte-americana, com a progressiva reincorporação dos estados derrotados. Uma guerra, contudo, não termina sem deixar marcas. A vitória do Norte fez com que se abolisse a escravidão em todo o território nacional. Por não acatarem o projeto do Norte, já nos anos finais da década de 1860, surgiram as primeiras tentativas de efetivação das políticas segregacionistas do Sul, derrotado. A convivência com os escravos recém-libertos, a igualdade de direitos e a convivência no mesmo espaço social era inaceitável para os adeptos do racismo. Assim, 
Leis de segregação racial haviam feito breve aparição durante a reconstrução, mas desapareceram até 1868. Ressurgiram no governo de Grant, a começar pelo Tennessee, em 1870: lá, os sulistas brancos promulgaram leis contra o casamento inter-racial. Cinco anos mais tarde, o Tennessee adotou a primeira Lei Jim Crow e o resto do Sul o seguiu rapidamente. O termo "Jim Crow", nascido de uma música popular, referia-se a toda lei (foram dezenas) que seguisse o princípio "separados, mas iguais", estabelecendo afastamento entre negros e brancos nos trens, estações ferroviárias, cais, hotéis, barbearias, restaurantes, teatros, entre outros. Em 1885, a maior parte das escolas sulistas também foram divididas em instituições para brancos e outras para negros. Houve "leis Jim Crow" por todo o Sul. Apenas nas décadas de 1950 e 1960 a Suprema Corte derrubaria a ideia de "separados, mas iguais". Dentro dessa postura segregacionista surgiu uma corrente ainda mais extremada, que defendia, em última instância, o extermínio da "população inferior". Desse grupo emergiu a Ku Klux Klan (KKK) [...] criada em Nashville, em 1867 (KARNAL; PURDY et al., 2007, p. 146).

A segregação racial norte-americana prosseguiu pelo século XX. A convivência social foi marcada pela separação entre negros e brancos nos mais diversos espaços. A partir das lutas sociais e da resistência dos movimentos sociais, o governo ampliou a dessegregação. Em 1954, a decisão da Suprema Corte sobre o caso Brown v. Board of Education of Topeka foi emblemático. Os pais de uma criança de sete anos, Linda Brown, protestaram judicialmente contra a segregação escolar e tiveram sucesso. $O$ sucesso da petição é considerado decisivo para a ampliação dos direitos civis dos segregados com "um lugar destacado na literatura da liberdade" (KLUGER, 2004, p. XII, tradução nossa). Por causa dele, as divisões raciais entre estudantes brancos e negros em escolas públicas passou a ser considerado inconstitucional afirmando-se que "instalações educacionais separadas são inerentemente desiguais" (KLUGER, 2004, p. 793, tradução nossa).

Em 1955, no Alabama, a costureira negra Rosa Parks (1913-2005) tomou o ônibus e assentou-se em dos lugares da frente reservados para brancos. Ela se recusou a dar seu lugar a um deles por pedido do motorista. Foi presa e enquadrada por desobediência das leis da cidade de Montgomery (WILLIAMS; GREENHAW, 2006). O simbolismo do gesto de Rosa Parks é tão forte que nos dias atuais é ela é reverenciada como a mãe dos direitos civis. Em 1957, dois fatos importantes ocorreram no mês de setembro: as repercussões do caso dos estudantes de Little Rock no dia 4, e a promulgação da Lei dos Direitos Civis, no dia 9. O direito ao voto foi garantido a todos cidadãos. Mais uma vez, a reforma da lei garantiu direitos negados na lei anterior, de 1895. A segregação racial chegou formalmente ao fim com a Lei dos Direitos Civis, promulgada em 2 de julho de 1964, assinada pelo presidente Lyndon B. Johnson. De maneira geral, podemos afirmar que o movimento dos direitos civis compreendeu o período que vai de 1954 a 1980. Já o movimento dos direitos civis dos negros dos Estados Unidos da América teve sua efervescência entre 1955 e 1968, 
conseguindo reformas para a abolição da segregação racial e ampliando direitos com o surgimento de movimentos negros como o Black Power e os Panteras Negras. Não houve uma mudança social sem luta ou resistência.

\section{Reflexões sobre Little Rock: apontamentos}

Hannah Arendt escreveu o ensaio Reflexões sobre Little Rock em 1957-1958. Ela já havia publicado uma das mais importantes obras sobre o totalitarismo na Alemanha em 1951, intitulado Origens do totalitarismo, seguido da coletânea de ensaios Entre o passado e o futuro, de 1954 e de $A$ condição humana, de 1958. Era uma autora conhecida por suas opiniões políticas dadas em mais de quarenta artigos para revistas alemãs e norteamericanas até 1959.

Contudo, o artigo Reflexões sobre Little Rock (1959) e o livro Eichmann em Jerusalém, publicado em 1963, que lhe renderam as maiores críticas e estão entre os seus escritos mais polêmicos no conjunto de sua obra. Em Eichmann em Jerusalém Arendt foi acusada de ser insensível com a questão judaica e mesmo incentivar uma visão negativa em relação aos judeus na Segunda Guerra Mundial (YOUNG-BRUEHL, 1997, p. 310-334). Sobre os eventos em Little Rock, Arendt escreveu o artigo com suas opiniões e tentou publicar na revista judaica Commentary, mas teve seu pedido negado. Somente em 1959 a revista Dissent publicou o artigo com a seguinte nota introdutória:

As circunstâncias em que Miss Arendt escreveu pela primeira vez, mas não publicou seu artigo são descritos em sua introdução. Nós o publicamos não porque concordemos com ela - muito pelo contrário!, mas porque acreditamos na liberdade de expressão, mesmo para pontos de vista que nos parecem totalmente equivocados. Por causa da estatura intelectual da Sra. Arendt, a importância de seu assunto e o fato de que uma oportunidade anterior para imprimir seus pontos de vista havia sido retirada, sentimos que é um serviço permitir que sua opinião, e as refutações a ela, agora sejam dadas livremente. Pedimos a atenção de nossos leitores para os comentários críticos após a leitura do artigo da Sra. Arendt. Na próxima edição, ela terá, naturalmente, a oportunidade de responder aos seus críticos; e dentro dos limites do espaço, comentários fundamentados dos leitores serão impressos. EDITORES (ARENDT, 1959, p. 45, tradução nossa).

A controvérsia do artigo arendtiano se situa na moldura da questão negra (negro question) norte americana em que as emoções estavam a flor da pele. Arendt nunca foi a favor da segregação racial. Era contrária à discriminação racial. Contudo, quando particulariza suas reflexões e julgamentos sobre Little Rock e a decisão da Suprema Corte no caso Brown vc. Board of Education of Topeka, é acusada de parecer "antipática e até mesmo insensível" (YOUNG-BRUEHL, 1997, p. 278) com as causas da dessegregação. Nesse sentido, o artigo de Arendt tornou-se "objeto de incompreensão, de indignação e de condenação em que análises de Little Rock pareciam contraintuitivas numa América que era 
cada vez mais confrontada com a 'questão negra' e as demandas da NAACP - National Association for the Advancement of Colored People (BENTOUHAMI, 2008, p. 162, tradução nossa). Além do mais, Hannah Arendt "foi criticada por sua 'cegueira' ao significado sociopolítico da raça e do racismo no Ocidente", advinda de uma rigidez na "aplicação das categorias filosóficas" do "público, o privado e social aos eventos de Little Rock". Ademais, por omitir "os esforços políticos dos afro-americanos" e de "sua compreensão errônea do significado sociopolítico da raça e do racismo nos Estados Unidos". Alguns dos críticos atuais acusam-na de "ignorância branca" pois o artigo sobre Little Rock constituiria "um erro epistêmico fundamental na obra de Arendt e, como tal, fortalece as atuais explicações da 'cegueira' de Arendt à história e aos esforços políticos dos afro-americanos" (BURROUGHS, 2015, p. 52). Contudo, uma leitura atenta e disposta a relacionar o artigo sobre Little Rock ao conjunto da produção política arentiana pode nos levar a conclusões interessantes para os movimentos sociais uma vez que "os conceitos desenvolvidos [...] para definir o exercício político são bastante ricos" desde que "as pessoas se ajuntem para discutir uma situação comum e decidir agir em conjunto para mudar esta mesma situação" (DUVAL, 2008, p. 84) tornando possível uma intervenção nessas condições.

Portanto, o contexto social da questão negra norte-americana era propício às controvérsias. Compreender a visada arendtiana sobre Little Rock, alicerçada no conjunto de sua produção política, nos auxiliará na análise do evento e as suas diversas possibilidades de narração.

\section{E se eu fosse uma mãe negra ou branca?}

A luta da estudante Elizabeth Eckford em Little Rock apareceu para Hannah Arendt através de uma fotografia dos jornais. A adolescente "era perseguida por uma turba de crianças brancas, protegida por um amigo branco de seu pai, a face dando um testemunho eloquente do fato óbvio de que ela não estava precisamente feliz". A situação aconteceu "porque aqueles que nela apareciam foram diretamente afetados pela ordem do tribunal federal, as próprias crianças" (ARENDT, 2004b, p. 261). Para compreender o evento, Arendt buscou subjetivar o fato se perguntando (a) se fosse ela uma mãe negra ou (b) se fosse ela uma mãe branca do Sul.

Na primeira hipótese (a), afirma que "em nenhuma circunstância exporia meu filho a condições que dariam a impressão de querer forçar a entrada num grupo em que não era desejado", agindo para manter o orgulho próprio, ou seja, "se eu fosse uma mãe negra do Sul, sentiria que a decisão da Suprema Corte, involuntária, mas inevitavelmente, colocara o meu filho numa posição mais humilhante do que aquela em que ele se encontrava antes". Nesse sentido, "sentiria que a própria tentativa de começar a dessegregação na educação e 
nas escolas não tinha apenas deslocado, e muito injustamente, a carga da responsabilidade dos ombros dos adultos para os das crianças". A escola seria um lugar indevido para se iniciar uma reforma do mundo pois essa obrigação seria dos adultos. A questão passa pela positivação dos costumes na legislação. Por isso, "a questão real é a igualdade perante as leis do país, e a igualdade é violada pelas leis da segregação" uma vez que essas leis "impõem a segregação, e não por costumes sociais e maneiras de educar crianças" (ARENDT, 2004b, 261-263). Confundir o mundo dos adultos com a escola é um passo para politizá-la e acreditar que somente alterando suas regras o mundo será afetado, ou seja, com essa medida a segregação teria fim no futuro.

Na segunda hipótese (b), "novamente tentaria impedir que meu filho fosse arrastado para uma batalha política no pátio da escola" e "sentiria ser necessário o meu consentimento para quaisquer mudanças drásticas". Evidenciando a distinção entre a vida privada (família) e a vida pública (mundo) Arendt afirma que "concordaria que o governo tem uma participação na educação do meu filho na medida que essa criança deve crescer e se tornar cidadã," no entanto, "negaria que o governo tenha o direito de me dizer em que companhia o meu filho deva receber a sua instrução", uma vez que os direitos de os pais decidirem essas questões para os filhos até eles se tornarem adultos só são questionados pelas ditaduras." Mais uma vez Arendt insiste que a segregação está para além da escola, pois ela "é imposta pela autoridade governamental" (ARENDT, 2004b, 263-264).

Arendt explicita que o problema é a norma constitucional uma vez que "a discriminação e a segregação sejam regra em todo o país, elas são impostas pela legislação apenas nos estados sulistas". Assim "essa não é em absoluto uma questão acadêmica". Por isso, a relação entre política e educação em Little Rock está assentada na "ideia de que se pode mudar o mundo educando as crianças no espírito do futuro" (ARENDT, 2004b, p. 264265) quando, de fato, a escola é afetada diretamente pelo mundo que já existe no tempo presente.

A concepção de educação em Hannah Arendt nos auxilia a entender alguns de seus pontos de vistas nas hipóteses (a) e (b). O tema da educação em Arendt é problematizado no ensaio A crise da educação, publicado em 1958 (ARENDT, 1992, p. 221-247). Ela percebeu que a crise da educação norte-americana era uma das cristalizações do mundo moderno (a mais radical é o totalitarismo) da ruptura política ocidental com a tradição, com uma certa teoria da ação, de autoridade e de liberdade. A adoção dos preceitos da pedagogia do pragmatismo para reformar a educação uma sociedade em conflito espelhou a crise contemporânea em solo norte-americano.

De fato, Arendt discorda do pragmatismo de John Dewey (1859-1952) e das repercussões do pensamento pedagógico dele na educação muito pelo fato do "aprender fazendo" (Ing: learning by doing). Para Dewey, "o fim (resultados) da educação se identifica com os seus meios (processos) do mesmo modo, aliás, que os fins da vida se identificam 
com os processos de viver" e assim, "enquanto vivo, não me estou, agora, preparando para viver daqui a pouco, estou vivendo. Do mesmo modo, eu não me estou em um momento preparando para educar-me e, em outro, obtendo o resultado dessa educação" (DEWEY, 1971, p. 93). A ênfase da educação é dada ao aluno e suas experiências de vida. Arendt critica o pragmatismo afirmando que "seja qual for a conexão entre fazer e aprender [...] tende a tornar absoluto o mundo da infância" e "sob o pretexto de respeitar a independência da criança, ela é excluída do mundo dos adultos e mantida artificialmente no seu próprio mundo" (ARENDT, 1992, p. 242). Arendt afirmou que a questão fundamental da crise educacional norte-americana é a da responsabilidade dos adultos em relação às crianças e jovens, em suma, a crise do amor mundi (ARENDT, 2004c, p. 213-225; ASSY, 2015, p. 2024). Essa responsabilidade define a mediação a ser realizada entre crianças e jovens e a escola uma vez que "a educação é o ponto em que decidimos se amamos o mundo o bastante para assumirmos a responsabilidade por ele" e também, "onde decidimos se amamos nossas crianças o bastante para não expulsá-las de nosso mundo e abandoná-las a seus próprios recursos" (ARENDT, 1992, p. 247).

Para Arendt, a educação tradicional ocidental tem como marca a responsabilidade pelas crianças e jovens a fim de colocá-los pouco a pouco em contato com o mundo dos adultos, aquela esfera pública que existe antes da chegada deles e que permanecerá depois da morte. A função da educação é a conservação do mundo pela mediação entre adultos, crianças e jovens pois "faz parte da essência da atividade educacional, cuja tarefa é sempre abrigar e proteger alguma coisa: a criança contra o mundo, o mundo contra a criança, o novo contra o velho, o velho contra o novo" (ARENDT, 1992, p. 242).

Quando a educação antecipa as relações mundanas e centra-se nas poucas experiências das crianças e jovens que estão ainda em formação - crítica destinada ao pragmatismo - evidencia-se uma crise. Por isso, a responsabilidade pela introdução dos recém-chegados ao mundo é da educação e de seus dispositivos. No caso de Little Rock a escola foi colocada no centro de uma ação judicial de dessegregação em um país com leis de segregação. Por isso, Arendt discorda de que a escola deve ser a protagonista da dessegregação. A escola é um reflexo do mundo. Assim, afirma Arendt, "a fotografia me pareceu uma caricatura fantásticas da educação progressista" por negar e abolir "a autoridade dos adultos", negando "implicitamente a sua responsabilidade pelo mundo em que puseram os filhos e recusa o dever de guiar as crianças por esse mundo" (ARENDT, 2004b, p. 272). Mais uma vez, uma dura crítica arendtiana à instrumentalização política da educação.

\section{E se a lei não mudar? Quem é responsável pelo mundo?}


Continuando a exposição dos argumentos arendtianos sobre Little Rock, apresentamos dois conceitos importantes. O primeiro diz respeito à norma constitucional da igualdade e o segundo é sobre a responsabilidade pelo mundo comum.

$\left.1^{\circ}\right)$ O evento de Little Rock se relaciona diretamente com a tradição cultural racista e a omissão da legislação norte-americana. Para Arendt, "a atitude do país com a sua população negra está arraigada na tradição americana, e em nada mais" já que "a questão da cor foi criada por um grande crime na história dos Estados Unidos e só tem solução dentro da estrutura política e histórica da República" (ARENDT, 2004b, p. 266).

A República moderna para Arendt "é baseada na igualdade de todos os cidadãos" e, "como tal tem uma importância na vida política de uma república maior do que em qualquer outra forma de governo". Contudo, há um problema na igualdade. Segundo Arendt, este princípio "não é onipotente", ou seja, "não pode igualdar características naturais, físicas," uma vez que "esse limite só é atingido quando são eliminados os extremos das desigualdades da condição econômica e educacional", derivando daí um ponto crítico que é o fato de que "quanto mais igualdade permeia toda a estrutura da sociedade, mais as diferenças provocarão ressentimento, mais evidentes se tornarão aqueles que são visivelmente e por natureza diferentes dos outros" (ARENDT, 2004b, p. 268).

Sobre esse primeiro ponto, precisamos nos referir a outro contexto em que também o racismo predominou. No livro Origens do totalitarismo, Arendt já conceituava os problemas advindos do princípio regulador de que todos somos iguais perante a lei. Para ela, a ideia de igualdade universal entre os homens cunhada pela Revolução Francesa em 1789 - e que foi decisiva para a formação do conceito de Estado-nação na Europa - foi uma das "mais incertas especulações da humanidade moderna". Para Arendt, quanto mais uma nação se aproxima da igualdade de condições, mais difícil se torna desvencilhar-se da inevitável explicação a respeito das diferenças entre as pessoas e grupos (o que a princípio não é positivo nem negativo, mas poderia criar uma situação de conflito). Os grupos de iguais tendem a se fechar em relação aos outros e aprimorar suas diferenças. Para Arendt, "sempre que a igualdade se torna um fato social, sem nenhum padrão de sua mensuração ou análise explicativa," são diminuídas as chances "de que se torne princípio regulador de organização política, na qual pessoas têm direitos iguais, mesmo que defiram entre si em outros aspectos" (ARENDT, 2004a, p. 76).

A questão de fundo é que no mundo comum vivemos em pluralidade, não em igualdade. A norma da igualdade pode ser interessante formalmente falando, mas exige uma capacidade política avançada para lidar com os conflitos advindos da frieza da lei.

Os judeus europeus, por exemplo, quanto mais se aproximavam da igualdade, "mais surpreendentes se revelavam as ambivalências; de um lado, o ressentimento social contra os judeus, de outro - e ao mesmo tempo - uma atração peculiar por eles." É que os sentimentos ambíguos de proteção/favorecimento e ressentimento/discriminação resultaram 
em antissemitismo uma vez que "conseguiram envenenar a atmosfera social, perverter as relações sociais entre judeus e gentios e influenciar a conduta dos judeus" (ARENDT, 2004a, p. 77). Para Arendt, tanto a questão judaica na Europa quanto a questão negra norte-americana foram e são uma questão política e não somente social. Por isso, a compreensão do antissemitismo europeu interferiu diretamente na compreensão arendtiana de Little Rock, uma vez que o assimilacionismo judaico é bastante semelhante por seu aspecto de violência contra a condição racial de um grupo social. Talvez nesse sentido, consigamos captar a noção arendtiana de que primeiramente há um problema no mundo comum que é transferido para a escola. Queremos ver a igualdade para todos, sem se preocupar com o seu grau de violência inerente na padronização cultural. Está em jogo aqui a capacidade de resistência dos movimentos sociais em garantir sim, seus direitos, mas de manter a sua identidade em prol da manutenção de suas características específicas.

Um problema colocado aos judeus -mas que se aplica por analogia à questão negra: o que fizeram eles para combater a discriminação social e política na Europa do século XIX e primeiras décadas do século XX? Segundo Arendt, o "destino social do judeu médio foi determinado por sua eterna falta de decisão." Para os judeus a questão judaica não era uma questão política - pois "havia perdido todo o significado político, mas obcecava suas vidas pessoais e influenciava suas decisões com redobrada tirania." A condição política judaica na Europa "tornava-se uma amarga realidade" em que "não era fácil deixar de se assemelhar ao 'judeu' e permanecer judeu; fingir não ser como os judeus e, contudo, demonstrar com suficiente clareza a sua judeidade" (ARENDT, 2005, p. 90). Assim, a questão judaica foi vivenciada dramaticamente no interior de cada judeu, não na vida pública, não como reação a uma condição política imposta pela sociedade europeia. Podemos inferir que no caso de Little Rock a crítica de Arendt mantém-se inalterada em relação à questão judaica: a política é a capacidade de agir em concerto, em comum, e nos obriga a agir no espaço público coletivamente, através de uma decisão que trará consequências para o grupo.

$2^{\circ}$ ) Uma questão importante para Arendt foi o fato de a escola pública ser o lugar onde a lei incidiu prioritariamente, obrigando as crianças e jovens a resolver uma situação que nem mesmo a legislação ainda havia resolvido. De fato, a responsabilidade pelo mundo comum e suas leis é dos adultos o que "sobrecarregaria as crianças, brancas e pretas, com a elaboração de um problema que os adultos por gerações se confessariam incapazes de resolver" e por isso que, conclui Arendt, "ninguém vai achar fácil esquecer a fotografia reproduzida nos jornais e revistas em todo o pais" (ARENDT, 2004b, p. 271).

O mundo é um espaço coletivo de convivência, construído pela capacidade humana do trabalho e reconstruído continuamente pela ação, que é "a única atividade que se exerce diretamente entre os homens sem a mediação das coisas ou da matéria, corresponde à condição humana da pluralidade, ao fato de que homens, e não o Homem, vivem na Terra e 
habitam o mundo" (ARENDT, 2005, p. 15). Assim, a conclusão arendtiana é de que somos todos responsáveis pelo mundo que construímos e reformamos pela ação uma vez "nenhum homem pode ser soberano porque a Terra não é habitada por um homem, mas pelos homens" (ARENDT, 2005, p. 246).

A responsabilidade pelo mundo comum exige que a educação seja um espaço de preparação das crianças e jovens para agir no mundo com autonomia. O amor mundi é a responsabilidade pelo que estamos fazendo ao agir em liberdade. As gerações humanas se sucedem e deixam de herança para os que estão adentrando no mundo pelo nascimento o que foi feito. Nesse sentido, a qualidade da herança que deixaremos para as futuras gerações, leva à ideia de que "só podemos escapar a responsabilidade política e estritamente coletiva abandonando a comunidade, e como nenhum homem pode viver sem é pertencer a alguma comunidade, isso significa simplesmente trocar uma comunidade por outra, e assim um de responsabilidade por outro" (ARENDT, 2004c, p. 217). O caso Little Rock é emblemático nesse sentido pois, evidencia que há uma esperança vazia e imaginária no futuro sem o comprometimento da ação no espaço coletivo, ou dizendo de outra maneira, para Arendt, os adultos se omitem na ação e deixam a cargo da educação e das crianças e jovens a resolução dos problemas do mundo comum.

Portanto, o caso Little Rock apresenta um problema político em relação à igualdade de direitos que Arendt acredita ser formalmente fundamental ter sua garantida conquistada, mas que pode levar a um assimilacionismo negador da identidade do grupo. É preciso ter capacidade de resistência para não perder a pluralidade, a diversidade. Outro problema é o da responsabilidade pelo mundo comum, o amor mundi, mundo que será herdado pelas futuras gerações e é uma construção coletiva, sujeita à pluralidade humana. O amor mundi em Arendt é o respeito ao tempo de maturação das crianças e jovens na educação pela escola para agir no mundo (ALMEIDA, 2011, 52-90).

\section{Os movimentos sociais, a visibilidade e o discurso}

Para Hannah Arendt a modernidade tardia, ou seja, o mundo depois da Segunda Guerra Mundial, passou a não dialogar mais com a tradição de ação no espaço público herdada dos gregos e dos romanos, nas experiências da polis e da res publica.

A decadência da ação surgiu como uma crise do mundo moderno, configurada na desvalorização do espaço público em que os problemas da comunidade são discutidos e onde somos ouvidos e ouvimos os outros, num exercício de liberdade. Uma crise da ação, esta capacidade humana de estar com os outros, em pluralidade. A ação entendida como um poder coletivamente compartilhado no espaço entre os homens.

Assim, no pensamento arendtiano, propõe-se um olhar generoso para outras experiências do passado político a fim de iluminar as discussões atuais. Nesse sentido, 
recupera o conceito de ação na polis. Na Grécia Antiga, a polis, e mais objetivamente a ágora, era o espaço público da liberdade, situando-se "exclusivamente na esfera política" uma vez que "ser livre significava ao mesmo tempo não estar sujeito às necessidades da vida nem ao comando do outro e também não comandar" não significando "domínio, como também não significava submissão" (ARENDT, 2005, p. 40-41). Mas não apenas na polis grega, mas também na res publica romana havia "a garantia contra a futilidade da vida individual, o espaço protegido contra essa futilidade e reservado à relativa permanência, senão à imortalidade, dos mortais" (ARENDT, 2005, p. 66).

A polis e a res publica eram espaços de discurso e de ação, resultando daí que a palavra pode ser um ato intersubjetivo, plural, coletivo, público. Assim, "a organização da comunidade que resulta do agir e falar em conjunto, e o seu verdadeiro espaço situa-se entre as pessoas que vivem juntas com tal propósito, não importa onde estejam" (ARENDT, 2005, p. 211).

Arendt acredita que o movimento negro recupera em certa maneira o sentido tradicional de visibilidade e a capacidade de discurso em que "ser visto e ser ouvido por outros é importante pelo fato de que todos veem e ouvem de ângulos diferentes. E este é o significado da vida pública" (ARENDT, 2005, p. 67). O movimento negro ao lutar por direitos iguais acaba por incorporar um valor político em que aparece o ideal da isonomia que é, antes de qualquer direito, a liberdade para agir e falar no espaço púbico. Isonomia é ter visibilidade. Isonomia é ter direito ao discurso no espaço público.

Talvez alguns críticos de Arendt não tenham se atentado para os elogios da ação relacionados ao movimento negro por ocupar o espaço público e por propor discussões de âmbito nacional nos Estados Unidos da América a partir da luta social, da visibilidade pelos protestos e gestos contrários à segregação racial. Para ela, "em todas as regiões do país, não menos no Leste e no Norte com sua legião de nacionalidades do que no Sul mais homogêneo, os negros se salientam por causa de sua 'visibilidade'. Isso significa que eles "não são a única 'minoria visível', mas são a mais visível" (ARENDT, 2004b, p. 267). Assim, a visibilidade é uma exigência de isonomia, o direito a lutar por direitos e ao espaço público. O movimento negro na luta por direitos civis, sociais e políticos tornaram visíveis e incontornáveis para a sociedade norte-americana suas demandas. A visibilidade social é um dos fundamentos defendidos por Arendt, o aparecimento da pluralidade no espaço público.

Por isso, os negros "se parecem bastante com os novos imigrantes, que invariavelmente constituem a mais "audível" de todas as minorias e assim sempre são mais propensos a desperta sentimentos xenófobos." Contudo, "embora a audibilidade seja fenômeno temporário, raramente persistindo além de uma geração, a visibilidade dos negros é inalterável e permanente". Para Arendt, "essa não é uma questão trivial" uma vez que "na esfera pública em que nada conta menos que se possa fazer ver e ouvir, a visibilidade e a 
audibilidade são da maior importância". E não adianta "argumentar que essas são apenas aparências exteriores [pois seria] incorrer em petição de princípio" uma vez que "são precisamente as aparências que 'aparecem' em público, e as qualidade interiores, os dons de coração e mente, apenas são políticas na medida em que seu portador deseja expô-las em público, colocá-las na ribalta do mercado" (ARENDT, 2004b, p. 267-268). Ouvir e ser ouvido, ver e ser visto no espaço público da ação são os fundamentos da política em Arendt. Para ser ouvido e visto é preciso uma decisão política que implica uma responsabilidade com o mundo comum.

Assim, a ação e o discurso são essencialmente humanos e essencialmente políticos. E são as marcas das manifestações do movimento negro ao Sul dos Estados Unidos. Enviar as crianças para a escola, por exemplo, pode ser avaliado como um rompimento do isolamento radical pretendido pelas leis de segregação, que intencionavam exatamente a apatia política em que "estar isolado é estar privado da capacidade de agir" (ARENDT, 2005, p. 201).

As manifestações de Little Rock expressam a luta contra a violência da segregação racial pois se tornou uma luta política. A luta dos movimentos sociais é um embate constante contra o instrumento moderno de mudez do discurso e da invisibilidade. A violência, seja qual for a sua matriz, baseia-se na geração da inação, da apatia, do medo de agir e ser repreendido. Enquanto implemento voltado para a coação, para que seja alcançada obediência através de um comando efetivo, a violência é "muda, e por este motivo, a violência por si só, jamais pode ter grandeza." Arendt percebeu a mudez da violência no mundo moderno. Por isso, ela acreditava que "com o ser político, o viver numa polis, significava que tudo era decidido mediante palavras e persuasão, e não através de força ou violência." Com isso, "para os gregos, forçar alguém mediante violência, ordenar ao invés de persuadir, eram modos pré-políticos de lidar com as pessoas," ou seja, gestos "típicos da vida fora da polis, característicos do lar e da vida em família, na qual o chefe da casa imperava com poderes incontestes e despóticos" (ARENDT, 2005, p. 35-36).

É por isso que, para Arendt, não pode haver política sem liberdade (os movimentos sociais normalmente usam os gritos de guerra quando em manifestações públicas) uma vez que "o preceito de liberdade foi criado ao mesmo tempo, e não antes, que o homem" (ARENDT, 2005, p. 190). Não há política sem palavra. É pela palavra que o ser humano se faz político. A palavra é o elo entre os homens no plural, o que torna público sua subjetividade e os torna intersubjetivos. Assim, "os homens no plural, isto é, os homens que vivem e se movem e agem neste mundo, só podem experimentar o significado das coisas por poderem falar e ser inteligíveis entre si e consigo mesmos (ARENDT, 2005, p. 12). Isso se dá no espaço público, "o local onde os indivíduos se veem e são vistos, falam e ouvem. É onde ocorre o encontro com os outros, em princípios iguais, mas que se diferenciam por sua atuação, por seu discurso." É o espaço político primeiro, o lugar "da reunião pública, na qual 
cada um percebe-se em simetria e identifica-se como membro de uma mesma comunidade" (SCHIO, 2006, p. 44).

Portanto, "a ação e o discurso são, de acordo com Hannah Arendt, os modos pelos quais os seres humanos se revelam uns aos outros na teia das relações intersubjetivas" criando a possibilidade de criar novas histórias, uma vez que na pluralidade a história nada mais é que o "livro de muitos atores e narradores" (ARENDT, 2003, p. 235). Little Rock, apesar de todas as controvérsias, torna visível o desejo de liberdade de uma minoria social num determinado contexto histórico e isso referenda o sentido da política em Hannah Arendt.

\section{Considerações finais}

A dessegregação da escola de Little Rock é um marco para os movimentos sociais ligados aos direitos das minorias e dos negros no mundo. Elizabeth Eckford e mais oito adolescentes deram visibilidade ao racismo contra os negros do Sul ao aparecerem do espaço privado para o espaço público. Foram acompanhados de fotógrafos que registraram a polêmica. Por isso, discutimos o contexto de Little Rock a partir do controverso texto de Hannah Arendt, cuja principal insistência é na mudança legislativa para a garantia dos direitos a todos os negros.

De fato, para se ter visibilidade social é preciso entrar na "esfera dos negócios humanos" que "consiste na teia de relações humanas que existe onde quer que os homens vivam juntos." As histórias acontecem na vida em comum pois são tecidas, tramadas, cerzidas como "resultado da ação e do discurso" em que os agentes se revelam pela palavra, pela voz, pelo gesto. A história não tem apenas um autor ou apenas um produtor. É a soma das ações de muitos agentes, de muitos quereres, de muitas intenções. Por isso, a história não é o resultado da ação individualista pois um de seus mobilizadores para a transformação é a política, a vida em comum, em que se escreve "livro de histórias da humanidade, com muitos autores e narradores" (ARENDT, 2005, p. 196-197). Nesse sentido,

A veracidade dos fatos nunca é forçosamente verdadeira. Os historiadores sabem como é vulnerável a textura de fatos na qual passamos nossa vida cotidiana; está sempre em perigo de ser perfurada por mentiras comuns, ou ser estraçalhada pela mentira organizada de grupos, classes ou nações, ser negada ou distorcida, muitas vezes encoberta cuidadosamente por camadas de falsidade, ou ser simplesmente deixada cair no esquecimento. Os fatos necessitam de testemunho para serem lembrados e de testemunhas de confiança para se estabelecerem, para que possam encontrar um abrigo seguro no domínio dos assuntos humanos (ARENDT, 2006, p. 16). 
Little Rock comprova que os movimentos sociais são fundamentais para as mudanças no mundo comum. A luta contra a segregação racial e suas consequências para o amor mundi são muito importantes uma vez que se pretende deixar de herança para os recém-chegados pelo nascimento um espaço coletivo de convivência melhorado, mais humanizado. A responsabilidade por uma sociedade mais justa é de todos os movimentos sociais e de todos e todas que acreditam que as memórias coletivas precisam ser narradas para iluminar o nosso tempo presente. Por isso, demos visibilidade para duas mulheres na nossa narrativa: Elizabeth Eckford e Hannah Arendt que se encontraram um dia numa fotografia de jornal e foram eternizadas de maneiras diferentes por suas posições políticas.

\section{REFERÊNCIAS}

ALMEIDA, Vanessa Sievers de. Educação em Hannah Arendt: entre o mundo deserto e o amor ao mundo. São Paulo: Cortez Editora, 2011.

ARENDT, Hannah. Crises da república. 2 ed. São Paulo: Perspectiva, 2006.

ARENDT, Hannah. Homens em tempos sombrios. São Paulo: Cia. das Letras, 2003.

ARENDT, Hannah. Origens do totalitarismo. São Paulo: Cia. das Letras, 2004a.

ARENDT, Hannah. Reflexões sobre Little Rock. In: ARENDT, Hannah. Responsabilidade e julgamento. São Paulo: Cia. das Letras, 2004b, p. 261-281.

ARENDT, Hannah. A condição humana. 10 ed. Rio de Janeiro: Forense Universitária, 2005.

ARENDT, Hannah. A crise da educação. In: ARENDT, Hannah. Entre o passado e o futuro. 3 ed. São Paulo: Perspectiva, 1992, p. 221-247.

ARENDT, Hannah. Responsabilidade coletiva. In: ARENDT, Hannah. Responsabilidade e julgamento. São Paulo: Cia. das Letras, 2004c, p. 213-225.

ASSY, Bethania. Ética, responsabilidade e juízo em Hannah Arendt. São Paulo: Perspectiva, 2015.

BENTOUHAMI, Hourya. Le cas de Little Rock Hannah Arendt et Ralph Ellison sur la question noire. Tumultes, Paris, n.30, v. 1, 2008/1, p. 161-194.

BURROUGHS, Michael D. Hannah Arendt, "Reflections on Little Rock" and white ignorance. Critical Philosophy of Race. Pennsylvania, n.1, v.3, 2015, p. 52-78.

DEWEY, John. Democracia e educação. Introdução à filosofia da educação. 3 ed. São Paulo: Ed. Nacional, 1959.

DUARTE, André. O pensamento à sombra da ruptura: política e filosofia em Hannah Arendt. São Paulo: Paz e Terra, 2000.

DUVAL, Michelle. L'action collective pensée par Hannah Arendt: comprendre l'agir ensemble pour le favoriser. Service Social, Laval, n. 541, 2008, p. 83-96.

GINES, Kathryn T. Hannah Arendt and the negro question. Bloominghton: Indiana Univer- 
sity Press, 2014.

KARNAL, Leandro; PURDY, Sean; FERNANDES, Luiz Estevam; MORAIS, Marcus Vinícius de. História dos Estados Unidos: das origens ao século XXI. São Paulo: Contexto, 2007. KLUGER, Richard. Simple Justice: The History of Brown v. Board of Education and Black America's Struggle for Equality. New York: Vintage Books, 2004.

MARGOLICK, David. Elizabeth and Hazel: Two Women of Little Rock. New Haven: Yale University Press, 2011.

SCHIO, Sônia Maria. Hannah Arendt: história e liberdade (da ação à reflexão). Caxias do Sul: EDUCS, 2006.

WILLIAMS, Donnie; GREENHAW, Wayne. The Thunder of Angels. The Montgomery bus boycott and the people who broke the back of Jim Crow. Chicago: Lawrence Hill Books, 2006.

YOUNG-BRUEHL, Elizabeth. Por amor ao mundo: a vida e a obra de Hannah Arendt. Rio de Janeiro: Relume-Dumará, 1997. 